Japan. J. Med. Sci. Biol., 25, 33-41, 1972

\title{
A POSSIBLE ROLE OF POSTERIOR HALF OF LARVAL BODY ON THE PUPATION OF THE FLESHFLY, SARCOPHAGA PEREGRINA
}

\author{
TETSUYA OHTAKI \\ Department of Medical Entomology, National Institute of Health, \\ Shinagawa-ku, Tokyo 141, Japan
}

(Received: December 12, 1971)

\begin{abstract}
SUMMARY : In mature larvae of the fleshfly ligatured tightly at the middle of the body, both anterior and posterior halves failed to pupate in dry condition, where intact larvae usually pupate in $17 \mathrm{hr}$. When the ligatures were loosened after a certain period, the paralized larvae began to pupate in 16-18 hr.

Single injection of ecdysterone of $10 \mu \mathrm{g}$ per $\mathrm{g}$ body weight induced full pupariation of the isolated anterior and posterior parts, showing that the blocked pupation in both parts of ligatured larvae is due to prevention of synthesis and secretion of ecdysone in the ring gland. Severance of the peripheral nerves just behind the ganglionic mass or of the recurrent nerves just in front of the proventricle did not show any influence upon the pupation time. Artificial shrinking of the crops did not accerelate pupation in wet condition, nor continuous supply of oxygen reduced the duration till pupation of the anterior parts.

When ligations were applied at the level behind the 10th segment larger anterior parts pupated mostly within $40 \mathrm{hr}$.

These results suggest that some humoral factor derived from a certain region in posterior segments, probably located in 11th to the last segments, may play an important role in synthesis of ecdysone at the ring gland.
\end{abstract}

\section{INTRODUCTION}

Mature larvae of the fleshfly, Sarcophaga peregrina, can not pupate* as long as they are kept in contact with water. If the mature larvae are transferred to dry condition, the initiation of puparium formation takes place usually in $17 \mathrm{hr}$ at $25 \mathrm{C}$.

It has generally been recognized that pupation of Cyclorrhapha is controlled by the brain through its neurosecretion, brain hormone, which activates the ring gland to synthesize and release a moulting hormone, ecdysone. It is also considered that when the larvae grow fully and reach a state ready to pupate, some internal stimuli or "feel" of changing the environmental condition provokes the brain to liberate the neurosecretion. Therefore, delayed pupation of fleshfly larvae in wet condition may be attributed to a temporal prevention of the release of brain hormone.

In a previous paper (Ohtaki, 1966), the author reported that tight ligation at the

\footnotetext{
* The word "pupation" or "pupate" used here covers a series of events beginning
} puparium formation to true pupation, unless otherwise specified.

大滝哲也（国立予防衛生研究所 衛生昆虫部） 
level between 7 th and 8 th segments of mature larvae prevents pupation in both anterior and posterior parts, even they were placed in dry condition. When a larva is ligatured at this level, the brain and ring gland are located anterior to the ligature. Thus the events led us to a question why the anterior part fails to pupate in the dry condition.

Several explanations can be put forward to account for the unexpected prevention of pupation by the ligation. This may be due to (a) insufficient synthesis of ecdysone following separation of the anterior part from the posterior part, (b) sensory stimuli from the site of ligation inhibiting liberation of neurosecretion from the brain, (c) an inhibitory factor of the enzyme system taking part in the process of darkening and hardening of the cuticle, or (d) else others.

Having studied the hormonal control of pupation in the blowfly, Fraser (1959) postulated that when feeding ceases, the stomatogastric nerves, as a result of release of tension in the crop, transmit a nervous stimulus to the brain to activate the neurosecretory system. Zdarek and Fraenkel (1971) also speculated that proprioceptors on the wall of the crop, signaling the repletion of the crop, provide the specific stimulation for the CNS to inhibit release of prothoracotropic hormone. This interpretation might be substantiated by the fact that the crop of fleshfly larvae, which is usually filled by air in wet condition, gradually shrinks into minimum size after transferred to dry condition.

Recently, Price (1970) reported that the anterior halves to ligatures applied at the middle of the body of Calliphora larvae of ten pupated more slowly than the posterior ones, and that the isolated middle parts made by two ligatures did not pupate. Hence, he claimed that a factor inhibiting pupation is produced in the middle of the larval body at the time of puparium formation.

An alternative hypothesis was proposed by Weir (1970) from the ligation experiments on Calpodes ethlius that ecdysone is produced not in the prothoracic gland but in the posterior part of the larvae. In Bombyx, Moriyama and others (1970) showed synthesis of ecdysone from cholesterol in isolated trunks of the last instar larvae. Furthermore, Romer (1971) reported that ecdysone was synthesized from cholesterol in the oenocytes in Tenebrio larvae. However, these seem unlikely in light of the present knowledge based upon accumulated data on the role of prothoracic gland obtained by many investigators. Extirpation of the ring gland from mature larvae before a critical period results in persistent larvae (Possompes, 1953). Isolated imaginal discs cultured in the adult male abdomen (Bodenstein, 1943) or in vitro (Kuroda and Yamaguchi, 1956) continue to develop if larval ring gland is implanted at the same time, but not without the ring gland. Ultrastructural studies on the prothoracic gland of Blattarian species (Scharrer, 1964) and the ring gland of Drosophila (King, Aggarwal and Bodenstein, 1966) showed that feature of the gland cells revealed the known steroidal nature of the secretory product involved.

Ligation itself gives rise to intense morphological and physiological injuries; i. e. obstruction of systemic circulation of the haemolymph, insufficient supply of oxygen by impaired tracheal system, paralysis by severance of the nerves, blocking of air or food passage through the alimentary canal, etc. The failed or delayed pupation of ligatured anterior halves may be due, directly or indirectly, to one or more physiological disturbances caused by ligation.

The present study was designed to clarify what is the main factor for failed or 
delayed pupation of the ligatured anterior parts and to explain the mode of action of the endocrine system responsible for pupation of the fleshfly.

\section{MATERIALS AND METHODS}

Experiments were carried out on the fleshfly, Sarcophaga peregrina, maintained routinely in this laboratory. Rearing and maintenance of this species were described in detail in the previous paper (Ohtaki, 1966).

When the larvae became fully matured, they were transferred into plastic cases containing sufficient amount of water to cover the bottom. After stored for further four or five days in the cases, larvae were subjected immediately to ligation or operation (Fig. 1). In this stage of larvae, extirpation of the ring gland resulted in persistent larvae.

Biological assays of ecdysone in the ligatured anterior and posterior parts were done by the same method as described by Ohtaki, Milkman and Williams (1968).

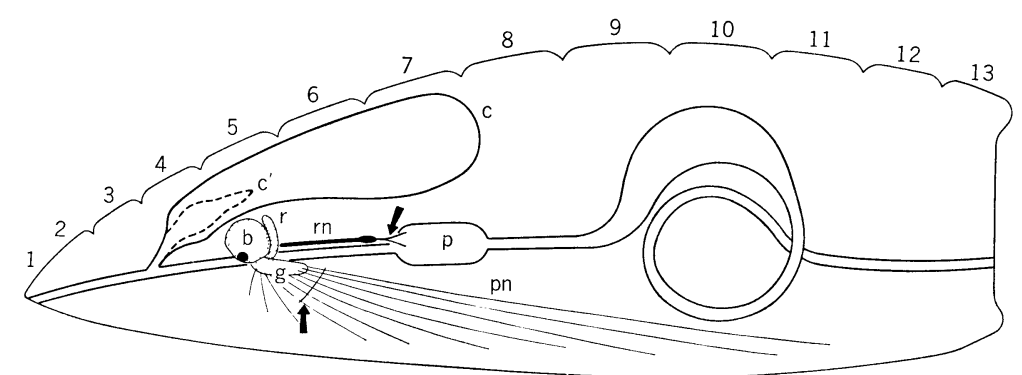

Fig. 1. Schematic explanation of the experiments, showing brain (b), crop $(\mathrm{c})$, shrinked crop $\left(\mathrm{c}^{\prime}\right)$, ganglionic mass $(\mathrm{g})$, proventricle $(\mathrm{p})$, peripheral nerves (pn), ring gland $(\mathrm{r})$, recurrent nerve $(\mathrm{rn})$, and segments (1-13).

The arrows show the positions of severance of nerves.

Severances of the peripheral nerves and the recurrent nerves were carried out by means of forceps through incised integument on the ventral side. Cutting off of the oesophagus was also done in the same way. To cause shrinkage of the crop, the dorsal skin was incised just above the crop, and a small hole was made on the crop by forceps inserted through the incision. Then, air filled in the crop was pushed out through the hole by pinching the body side with another forceps. All surgeries were done in a physiological saline solution. After such treatment, the test animals were placed either in dry or wet condition.

In another series of experiments, ligatured larvae were placed under continuous supply of oxygen. For this purpose, a desiccator of 51 volume was used. Oxygen was introduced into the desiccator at a rate of 1001 per hr through the glass tube inserted through the cover of the desiccator to the bottom. The oxygen stream was exhausted through the other tubing fitted to the top of the cover.

The rearing of the materials and all the experiments were carried out at $25 \mathrm{C}$. 


\section{RESULTS}

\section{Experiment 1. Effects of Ecdysone on Pupation of the Separated Anterior and Posterior Halves}

Each of 20 larvae were tied with two ligatures applied closely each other at the 7th segment, and the larval body was divided into two pieces between the two ligatures. Immediately, each part received ecdysterone of $10 \mu \mathrm{g}$ per $\mathrm{g}$ body weight. All pupated in 8.5-9 hr. This latent period from the injection of ecdysone to puparium formation is almost equal to that observed in intact animals after the release of a sufficient amount of ecdysone or in whole body injected with ecdysones (Ohtaki et al., 1968).

For determination of ecdysone titer in the ligatured anterior and posterior halves at the time of puparium formation, one hundred $8.5 \mathrm{hr}$ dry larvae were ligatured at the 7th segment and kept further in dry condition for additional $8.5 \mathrm{hr}$. Then, the anterior and posterior parts of them were separated. At this time, nearly $75 \%$ of the anterior parts had already pupated and so did half of the posteriors. Hundred fragments of each were pooled and subjected to extraction of ecdysone.

One-twentieth of partially purified extract gave $20 \%$ puparium index of Sarcophaga assay in posteriors and $10 \%$ puparium index in anteriors. One hundred parts of the extracts were negative on the assay in both parts. Assuming $10 \%$ loss in the extraction procedure, it was estimated that $0.0024 \mu \mathrm{g}$ or less ecdysone was in each posterior part and $0.0009 \mu \mathrm{g}$ or less in anterior part (Fig. 2).

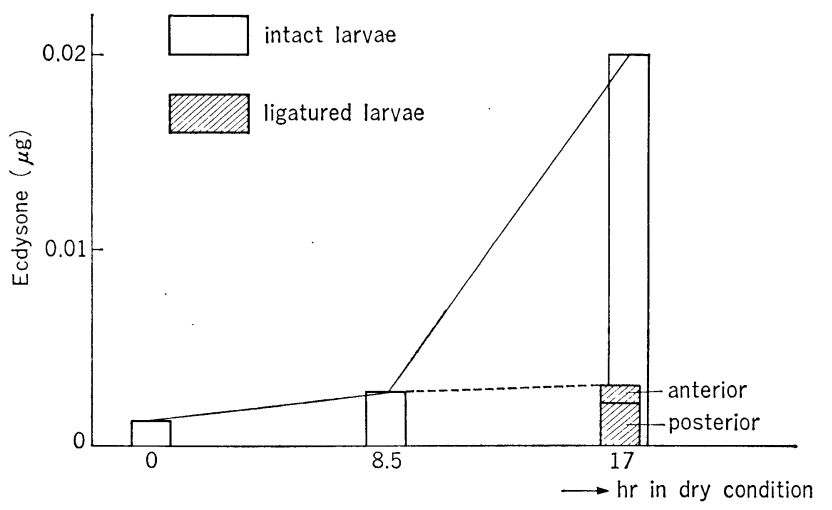

Fig. 2. Ecdysone titer in ligatured larvae compared with those in intact larvae.

\section{Experiment 2. Recovery of Blood Circulation by Removal of Ligature}

When ligature was applied tightly at the 6 th or 7 th segment of $0 \mathrm{hr}$ dry larvae and then immediately removed by cutting off the thread, the paralysed larvae pupated in 16-18 $\mathrm{hr}$ in dry place. They failed to transform themselves into the usual barrel shape, but darkening and hardening of larval cuticle occurred in a quite normal way. In further experiments, the larvae were freed from ligation after several hours. Pupation of these larvae began $17 \mathrm{hr}$ after loosening the ligature, irrespective of the period of preceding ligation (Fig. 3). 


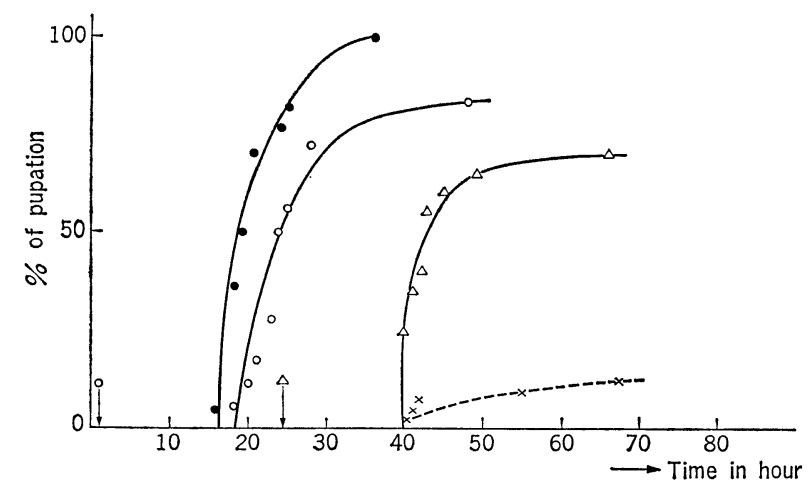

Fig. 3. Pupation curve after recovery in blood circulation by removing the ligature which had been applied for half an hour or $24 \mathrm{hr}$.

$\bigcirc-\bigcirc$ removal of the ligatures after $30 \mathrm{~min}$.

$\triangle-\triangle$ removal of the ligatures after $24 \mathrm{hr}$.

$\times--\infty$ continuous application of the ligatures.

- intact control.

The arrows show the times removing the ligatures.

\section{Experiment 3. Severances of Nerves}

Ten $0 \mathrm{hr}$ dry larvae were subjected to severance of the peripheral nerves. After all the pairs of nerves being distributed below the 6th segment were severed just behind the ganglionic mass, the larvae were placed in dry condition. Cutting the recurrent nerves was also done in other ten $0 \mathrm{hr}$ dry larvae. These two groups of larvae and other ten sham operated control animals began to pupate $16 \mathrm{hr}$ after the operation almost concurrently (Table 1 ).

These results apparently show that neither peripheral nor visceral nerves have any stimulating effect on the ring gland to synthesize and release ecdysone.

Table 1. Effects of severing the nerves on pupation of full grown larvae of fleshfly in dry condition

\begin{tabular}{|c|c|c|c|c|}
\hline \multirow{2}{*}{$\begin{array}{c}\text { Operation } \\
\text { severance of : }\end{array}$} & \multirow{2}{*}{$\begin{array}{c}\text { No. of larvae } \\
\text { operated }\end{array}$} & \multicolumn{3}{|c|}{ No. of larvae } \\
\hline & & not pupated & pupate & \\
\hline peripheral nerves & 10 & 0 & 10 (within & $\left.24 \mathrm{hr}^{*}\right)$ \\
\hline recurrent nerves & 10 & 0 & $10(\quad /$ & $\left."{ }^{*}\right)$ \\
\hline control & 10 & 0 & $10(\prime \prime$ & $\prime \prime *)$ \\
\hline
\end{tabular}

* No virtual difference from intact control

\section{Experiment 4. Artificial Shrinking of the Crop}

A total of 28 larvae were subjected to the operation in which the air filled crop was surgically made to shrink. As the control, the oesophagus was sectioned between the cephalic complex and the proventricle, leaving the crop swollen with air. After 
Table 2. Effects of artificially induced shrinkage of the crop on pupation of full grown fleshfly larvae in wet condition

\begin{tabular}{lccc}
\hline Operation & $\begin{array}{c}\text { No. of larvae } \\
\text { operated }\end{array}$ & $\begin{array}{c}\text { No. of permanent } \\
\text { larvae }\end{array}$ & $\begin{array}{c}\text { No. of pupated } \\
\text { (pupation time in } h r)\end{array}$ \\
\hline $\begin{array}{l}\text { Shrinkage of } \\
\text { crop }\end{array}$ & 28 & 21 & $7^{*}(38,40,42,45$, \\
$45,45,49)$ \\
$\begin{array}{l}\text { Sectioning of } \\
\text { oesophagus } \\
\text { (control) }\end{array}$ & 19 & 18 & $1^{*}(36)$ \\
\hline
\end{tabular}

* For full recovery from anaesthesia, the larvae were placed in dry condition for $1 \mathrm{hr}$ after the operation. Pupation in some larvae in wet condition may be due to this treatment.

recovery from anaesthesia, the operated animals were returned to wet condition. Number of pupated larvae and time of pupation were recorded for $50 \mathrm{hr}$ after returning to wet condition.

As shown in Table 2, the majority of the larvae did not pupate in wet condition, and if did, the time until pupation was remarkably prolonged.

\section{Experiment 5. Influences of Ligation Level to Pupation of the Anterior Parts}

Four groups, each consisting of thirty wet larvae were ligatured at various levels; between the 9 th and the 10th segments, the 10th and the 11th segments, the 11th and the 12th segments, or the 12th and the last segments. As shown in Table 3, if the ligatures were placed above the level of the 10th segment, pupation of the anterior parts was blocked, but the ligation below the 11th segment did not inhibit pupation in half of the larvae. These results suggest that ill supply of oxygen in the anterior parts by ligation is not the main cause of the failure in pupation.

In another experiment, pupation time of the anterior part of larvae ligatured at various levels and placed in continuous supply of oxygen was compared with that of the ligatured larvae kept in the stream of air. The results revealed, as shown in Fig. 4, that virtual accerelation of pupation in the anterior parts was not observed in oxygen. It was suggested, therefore, that something located in the part posterior to the 10th segment is responsible for induction of pupation.

Table 3. Effects of ligature level on pupation of anterior part in dry condition

\begin{tabular}{lccc}
\hline $\begin{array}{l}\text { Ligatured } \\
\text { between: } \\
\text { segments }\end{array}$ & $\begin{array}{c}\text { No. of larvae } \\
\text { ligatured }\end{array}$ & \multicolumn{2}{c}{ No. of anterior part pupated } \\
\hline 9 th $: 10$ th & 30 & 0 & within $40 \mathrm{hr}$ \\
10 th $: 11$ th & 30 & 0 & 0 \\
11 th $: 12$ th & 30 & $24 \mathrm{hr}$ & 1 \\
12 th $:$ the last & 30 & 1 & 14 \\
\hline
\end{tabular}




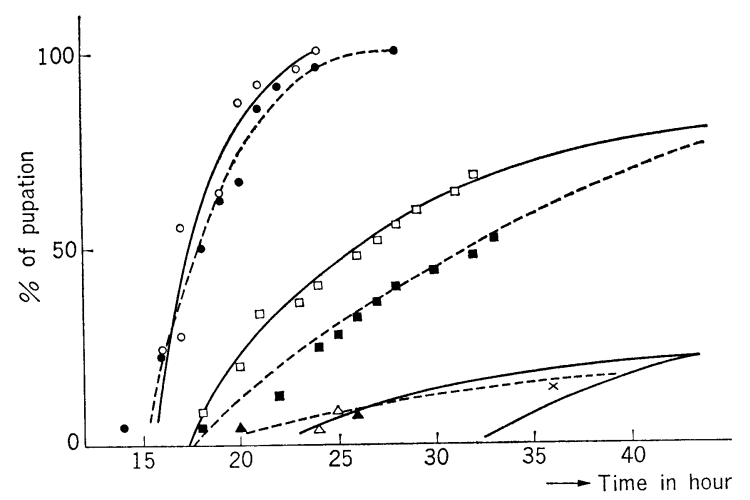

Fig. 4. Pupation of anterior parts of fleshfly larvae ligatured between the 6 th and the 7 th segments, the 9 th and the 10th segments, or the 11th and 12th segments, in continuous supply of oxygen or air.

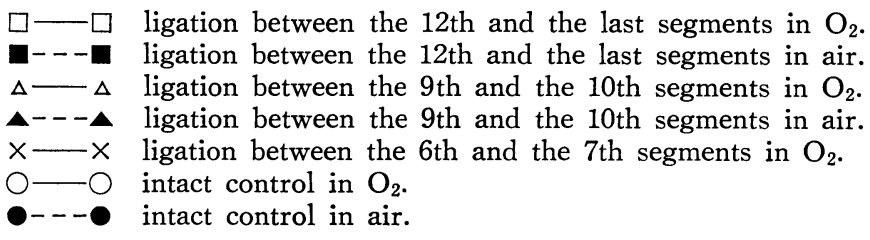

No anterior part ligatured between the 6 th and the 7 th segments pupated within $50 \mathrm{hr}$ in air stream.

\section{DISCUSSION}

Normal puparium formation induced by injection of ecdysone in both isolated anterior and posterior parts of larvae of $S$. peregrina indicates that the failed pupation by ligation is due not to insensitiveness of the target tissues to moulting hormone, but insufficient activation of the ring gland to synthesize and liberate enough moulting hormone for full pupariation. Blocked de novo synthsis of ecdysone in ligatured larvae was also confirmed by determination of ecdysone titer. The ecdysone titers in $8 \mathrm{hr}$ dry larvae and white puparia were known to be $0.0025 \mu \mathrm{g}$ and $0.02 \mu \mathrm{g}$ per animal, respectively (Ohtaki et al., 1968). The ecdysone titers in separated larval bodies were rather constant after ligation, no increase of ecdysone titer toward expected time of the puparium formation being observed. These results demonstrate that the failed pupation by ligation is due neither to ill supply of the substrates needed for tanning and darkening of larval cuticle, nor to presence of the phenol oxidase inhibitor which was postulated by Price (1970), but to a lack of stimulation for synthesis and release of ecdysone.

As shown in Experiment 2, if systemic circulation of blood was recovered by removing ligature, darkening and hardening of larval cuticle was to occur normally on the whole surface, showing that enough ecdysone to full pupariation was then secreted into blood.

Severance of the nerves or artificial shrinkage of the crop did not affect pupation. Therefore, it is thought that the agent responsible for activation of the ring gland is not transmitted via nerves but by blood circulation. The results of the last series of 
experiments showed that the 11 th and the 12th segments may play an important role in the endocine events leading the larvae to pupation. Posterior parts of the larval body are abundant in fat bodies. In our preliminary tests to know whether fat bodies produce the agent stimulating the ring gland, implantation of fat bodies from posterior parts into the isolated anterior was carried out. In the repeated experiments no case was seen in which induction or acceleration of pupation took place.

One could, therefore, postulate an alternative step in the control of pupation; a hormone other than ecdysone released by brain-ring gland system stimulates some abdominal tissue to synthesize and liberate ecdysone there. This interpretation would be supported by the results obtained by Moriyama et al. (1970). Weir (1970) proposed from the ligation experiments using Calpodes ethlius that the oenocyte is a candidate endocrine organ interacting with prothoracic glands in the control of the moulting. However, in fly larvae oenocytes are situated bilaterally in every abdominal segment with an exception of the last one (Bodenstein, 1950). Anterior part to the 10 th segment has several pairs of the oenocyte groups. Thus, from the evidences obtained in Experiment 5, the interpretation that the oenocyte is secreting ecdysone is not acceptable.

Until now, we have tied more than 10,000 Sarcophagid larvae at various level around the middle of the body at various developmental stages, but those animals, of which the part posterior to ligature had pupated earlier, were not found unless tracheal system in anteriors was injured or blocked.

From all the experimental data described here, it is likely that some agent drived from a certain region located in posterior segments, probably in the 11 th to the last segment, is transmitted via blood circulation, and is responsible for synthesis and release of ecdysone in the ring gland under the influence of neurosecretion released from the activated brain.

\section{ACKNOWLEDGEMENT}

The author wishes to express his hearty thanks to Dr. Syoziro Asahina, Chief of Department of Medical Entomology, the National Institute of Health for his encouragement. Cordial thanks are also expressed to Dr. Toshitaka Hidaka, Professor of Tokyo University of Agriculture and Technology, for reading the manuscripts and for the criticisms.

\section{REFERENCES}

Bodenstein, D. (1943): Hormones and tissue competence in the development of Drosophila. Biol. Bull., 84, 34-58.

Bodenstein, D. (1950): The postembryonic development of Drosophila. p. 275-267. In Biology of Drosophila, M. Demerec (ed.), Hafner Publishing Co., New York and London.

FRASER, A. (1959): Neurosecretion in the brain of the larva of the sheep blowfly. Lucilia ceasar. Quart. J. microscop. Sci., 100, 377-399.

KInG, R. C., AGgarwal, S. K. AND Bodenstein, D. (1966): The comparative submicroscopic morphology of the ring gland of Drosophila melanogaster during the second and third larvae instars. Z. Zellforsch., 73, 272-285.

KURODA, Y. AND YAMAGUCHI, K. (1956): The effects of the cephalic complex upon the eye discs of Drosophila melanogaster. Japan. J. Genet., 31, 98-103.

Moriyama, H., NAKanishi, K., King, D. S., OKaUchi, T., Siddall, J. B. AND HAFFerL, 
W. (1970): On the origin and metabolic fate of $\boldsymbol{\alpha}$-ecdysone in insects. Gen. Comp. Endocrinol., 15, 80-87.

Oнtaki, T. (1966): On the delayed pupation of the fleshfly, Sarcophaga peregrina RobineauDesvoidy. Japan. J. Med. Sci. Biol., 19, 97-104.

Ohtaki, T., Milkman, R. D. AND Williams, C. M. (1968): Dynamics of ecdysone secretion and action in the fleshfly Sarcophaga peregrina. Biol. Bull., 135, 322-334.

PossompÈs, B. (1953): Recherche experimentales sur le determinisme de la metamorphose de Calliphora erythrocephala Meig. Arch. Zool. Exp. Gen., 89, 203-364.

PRICE, G, M. (1970): Pupation inhibiting factor in the larva of the blowfly Calliphora erythrocephara. Nature, 228, 876-877.

ROMER, F. (1971): Häutungshormone in den Oenocyten des Mehlkäfers. Naturwissenschaften, $58,324-325$.

SCHARRER, B. (1964): The fine structure of Blattarian prothoracic glands. Z. Zellforsch., 64, 310-326.

WEIR, S. B. (1970): Control of moulting in a insect. Nature, 228, 580-581.

ZDAREK, J. AND FRAENKEL, G. (1971): Neurosecretory control of ecdysone release during puparium formation of flies. Gen. Comp. Endocrinol. 17, 483-489. 